Original Article (short paper)

\title{
Psychometric properties of the Questionnaire of Attitudes towards Doping in Fitness (QAD-Fit)
}

\author{
Ana Sofia R. Tavares ${ }^{1,2}\left[\right.$, Sidónio Serpa ${ }^{1}\left[\right.$, António Rosado ${ }^{1} \mathbb{0}$ \\ ${ }^{1}$ Universidade de Lisboa, Faculdade de Motricidade Humana, Cruz Quebrada, Lisboa, Portugal; ${ }^{2} H \& T R C$, Health \& Technology \\ Research Center, ESTeSL, Escola Superior de Tecnologia da Saúde de Lisboa, Instituto Politécnico de Lisboa, Lisboa, Portugal
}

\begin{abstract}
Aim: The purpose of this study was to test the psychometric proprieties of the Questionnaire of Attitudes towards Doping in Fitness (QAD-Fit), originally developed by Serpa and colleagues and adapted to Portuguese gym/ fitness context. Methods: A cross-sectional survey utilizing a web self-administered questionnaire was used. The sample was composed of $453 \mathrm{gym} / \mathrm{fitness}$ center practitioners, aged between sixteen and seventy-nine years old $(M=35.64$; $S D=13.08$ ), enrolled in several gym activities. Results: The confirmatory factorial analysis provided support to the four-factor structure proposed. All factors displayed good internal consistency, convergent validity, and discriminant validity. The multi-group analysis revealed cross-validity and the model's invariance. The correlation between QAD-Fit and the Doping-related Theory of Planned Behavior Measures (DRTPBM) revealed evidence of its concurrent validity. Conclusion: The findings of this research revealed that QAD-Fit is a psychometrically valid and reliable instrument to assess attitudes towards doping consumption in gym and fitness settings.
\end{abstract}

Keywords: attitudes towards doping, gym/fitness practitioners, confirmatory factor analysis.

\section{Introduction}

Within recreational sports, people using fitness centers come from a very wide range of demographics and backgrounds. Performance-enhancing substances (PES - e.g., stimulants, anabolic-androgenic steroids (AAS), erythropoietin, human growth hormone, and diuretics) are used by this kind of practitioners for many reasons and motives ${ }^{1}$. A recent systematic review $^{2}$ concluded that gym/fitness practitioners use PES, especially AAS, due to aesthetic reasons, generally driven by their dissatisfaction with physical appearance, followed by low self-esteem and the wish to become more attractive and desirable. The same study points out that the main motivation to use this kind of substances was to increase muscle mass and strength, to improve physical performance, to recover faster from previous training sessions, to prevent injuries and to manage body size/ weight. Alongside these reasons and motivations for the use of PES, perceived social pressure and peers influence on subjective norms, play an important influence towards a positive attitude towards PES use in gym users².

Taking into account that attitudes can be used to predict doping behavior ${ }^{3}$, anti-doping research should include, alongside with physiological and chemical approaches, sociological, behavioral and ethical studies of athletes' attitudes and beliefs towards the use of PES, since it seems to involve a set of essentially volitional behaviors ${ }^{4,5}$. However, the choice of using PES is regulated by a complex system of dynamic relations between social cognition and behavior, influenced by a range of circumstances, situations, and individual characteristics, that must be considered within the theoretical framework describing the pattern of these relations ${ }^{6}$. In this sense, though some psychological integrative models (eg., Sports Drug Control Model, Trans-contextual Model, Life Cycle Model) have been pointed out to clarify the use of PES in sport ${ }^{7,8}$, the Theory of Planned Behavior (TPB) is one of the most frequently used framework to explain athletes doping intentions and behavior ${ }^{9}$, since it offers descriptions and definitions that are more understanding about the specified construct and includes a discriminant validity of the constructs ${ }^{10,11}$. According to the $\mathrm{TPB}$, behavioral intention of the actions to assume or refuse a healthy behavior ${ }^{12}$ is determined by the individual's attitude towards the behavior, subjective norms and perceived the behavioral control (PBC) ${ }^{13}$.

Since individual's attitude towards the behavior reflects the evaluation of the consequences of engaging in the target behavior, attitudes are often used as a proxy for doping behavior, with the assumption that those who use PES will show greater leniency towards doping than those who do not ${ }^{5,14,15}$. To assess attitudes towards doping, a valid and reliable instrument is required ${ }^{15}$. However, Morente-Sanchéz, Femia-Marzo and Zabala ${ }^{4}$ stated that just a few studies used validated tools to assess attitudes towards doping, while the majority of researchers used ad hoc measurements without psychometric testing, which compromise the reliability and validity of the findings. In this way, ad hoc measures, developed and used for single research, without demonstrated reliability and validity should be avoided, since test scores are interpreted as the individual's attitude and inferences are made for a specific population ${ }^{15}$. 
In order to address this gap, several direct measures (self-report questionaire) of attitudes and thus behaviors have been proposed in doping research ${ }^{14}$. The Performance Enhancement Attitude Scale (PEAS) is an example of a selfreported explicit measure of a generalized doping attitude ${ }^{15}$. However, PEAS is used in doping research as other validated psychometric assessments, which measure an effective implicit doping attitude (eg., Doping Implicit Association Test, Doping Brief Implicit Association Test and Pictorial Doping Brief Implicit Association Test) only in terms of elite sport $^{6}$. Serpa, Leitão, Marcolino, Faria, Ramadas and Reis ${ }^{16}$ proposed a multidimensional model of attitudes towards doping in sports - "Questionnaire of Attitudes towards Doping in Sports" (QADS) based on the TPB. The goal was to create an instrument which measures the factors that influence the formation of young people's attitudes and, consequently, a better understanding of the triggering of doping behaviors ${ }^{17}$.

The Questionnaire of Attitudes towards Doping in Sports has four dimensions associated with doping behavior: (1) attitudes towards doping consumption; (2) beliefs, meaning the subject's beliefs regarding the effect of doping in order to improve performance; (3) intentions about the circumstances in which individuals think they would or would not take doping; and (4) subjective norms, that is, the subject's perception of what people who are significant to him think about the consumption of doping substances. It comprises 31 items, scored on a 7-point Likert type scale ${ }^{17}$. Several authors validated this instrument in different populations ${ }^{17}$. For example, Opdenacker, Vanden Auweele and Serpa ${ }^{18}$ studied a sample of young Belgian athletes with ages ranging from 14 to 18 years, and added 3 items to the factor subjective norms, because of the small number of items included in this factor. So the QADS used consisted of 34 items with 15 items belonging to the concepts of intentions, 7 items to attitudes, 7 items to subjective norms and 5 items to beliefs, showing a satisfactory internal consistency.

To date, and to our knowledge, QADS showed exploratory validity evidence and satisfactory reliability results in almost all the different populations tested ${ }^{17}$, but a more refined analysis was not performed, namely, a confirmatory factorial analysis. Therefore, the aim of this study was to analyze the psychometric proprieties of the QADS, terminologically adapted to the target population in this study - gym/fitness center practitioners and was designated as "Questionnaire of Attitudes towards Doping in Fitness" (QAD-Fit), in order to provide a psychometrically valid and reliable instrument. More specifically, we intended to analyze the factor structure as it was proposed by the QADS' authors. Furthermore, into a more refined analysis, we (i) tested the model to determine its internal consistency and convergent validity; (ii) tested the invariance of the structure with a cross-validation strategy; and (iii) explored the concurrent validity with a sample of Portuguese gym/fitness center practitioners.

Having a valid and reliable instrument that can provide measures of the factors that influence the formation of gym/fitness center practitioners'attitudes is essential, to better understand the triggering of doping behaviors in this specific population.

\section{Method}

\section{Participants and data collection}

A convenience sample of 453 Portuguese gym/fitness center practitioners, aged between sixteen and seventy-nine years old $(M=35.64 ; S D=13.08)$, participated in this research. The sample size required for this study that uses a structural equation model (SEM) was calculated by A-priori sample size calculator for SEM (Soper, 2017) ${ }^{19}$. Participants were involved in several gym activities (e.g., 57\% cardio fitness, 56.5\% bodybuilding, $27.8 \%$ stretching, $27.2 \%$ localized). From those, 277 were female and 175 males.

Prior to data collection, the study was reviewed by the University Ethics Board. Upon approval ( $\mathrm{N}^{\circ}$ 38/2017), participants were recruited by Gyms and Fitness center clubs that were invited and accepted to participate (by institutional e-mail / Facebook) and through a social network (Facebook).

The survey Web link directed potential subjects to an informed consent page, providing additional information regarding the study and detailing methods used to maintain confidentiality and anonymity. Then, an electronic version of the "Questionnaire of Attitudes towards Doping in Fitness" (QAD-Fit) and the Portuguese version of the Doping-related Theory of Planned Behavior Measures ${ }^{20}$ (for concurrent validity purpose) were completed via the same online link. The questionnaires took approximately 10 minutes to complete. No individually identifiable data were collected, Internet provider addresses were not logged, and data transfer was encrypted.

\section{Measures}

The "Questionnaire of Attitudes towards Doping in Sports" (QADS) is an originally Portuguese questionnaire that was developed by Serpa, Leitão, Marcolino, Faria, Ramadas, Reis ${ }^{16}$ and is based on the theory of planned behavior ${ }^{12}$. It includes four dimensions to evaluate attitudes ( 7 items), beliefs ( 5 items), intentions (15 items) and subjective norms (7 items), and its 34 items are scored on a seven-point Likert-type scale ranging from (1) totally disagree to (7) totally agree. The items $2,4,5,11,13,19,25,30$ and 32 , must be reversed ${ }^{16}$. A higher score would mean a more positive attitude towards doping consumption. The QADS was used within the sport context. Therefore, in the present study, we changed some of the items, in order to better describe the fitness context instead of the sport environment. For example, we replaced the word athlete by practitioner (items $1,2,5$ ) and we rephrased sentences, replacing sport expressions to fitness expressions, in order to focus the practitioner in the fitness context. In this study and after this adaptations, we designated the instrument as "Questionnaire of Attitudes towards Doping in Fitness" (QAD-Fit) (Appendix). Finally, the QAD-Fit was tested with 30 participants (pilot study) to ensure that the questionnaire was perfectly clear and understandable, which was confirmed immediately by means of an interview with each participant. 
Doping-related Theory of Planned Behavior Measures $(\text { DRTPBM })^{20}$ was translated to Portuguese, adapted and validated for this study, to be used for concurrent validity proposes, since that is known to accurately measure almost the same constructs as QAD-Fit. Once approval was obtained from the original scale author, the translation of the DRTPBM was performed, according to Beaton, Bombardier, Guillemin, Ferraz and Bosi ${ }^{21}$, using a five-stage process. In this way, a brief description of the psychometric validation of this scale will be presented in this article. The original version ${ }^{20}$ has four subscales, attitudes (6 items); subjective norms ( 2 items); perceived behavioral control (3 items); and behavioral intentions (3 items). According to Lucidi, Zelli, Mallia, Grano, Russo and Violani ${ }^{20}$, this scale was conceptualized through TPB, with reference to the motives or goals that adolescents typically report for doping use, such as seeking to improve performance and /or physical appearance. Items were answered on a five - point Likert scale.

\section{Data Analysis}

Data Analysis was performed using SPSS (version 22.0) and AMOS 22.0 (SPSS Inc. Chicago IL). A confirmatory factor analysis (CFA) was performed to assess the psychometric proprieties of the QAD-Fit instrument. The maximum likelihood (ML) method was used. Following the discovery of unsatisfactory fit, modification indices and standardized estimates were examined to evaluate for alternative models or probable item removals. To retain an item, a factor load equal to or greater than .50 within a single factor was used ${ }^{22}$.

Univariate skewness and kurtosis of items were examined, as well as multivariate normal distribution using Mardia's (1970) coefficient of multivariate kurtosis ${ }^{23}$.

Internal consistency (reliability) of the constructs was assessed through composite reliability, and we followed the recommendation of Fornel and Larcker ${ }^{24}$ to calculate composite reliability (CR), in which it is recommended that values $\geq .7$ indicate a proper value of CR.

Convergent validity was evaluated through the average variance extracted (AVE), whereby the values of AVE $\geq .5$ are appropriate indicators of convergent validity ${ }^{25}$.

Discriminant validity was established when the AVE for each construct went beyond the squared correlations between that construct and any other ${ }^{25}$. In order to identify QAD-Fit' factorial invariance, cross validation procedures were used with a multi-group analysis strategy ${ }^{26-28}$.

Assessment of model fit was based on multiple indicators ${ }^{29,30}$, namely: chi-square $\left(X^{2}\right)$ statistical test, the ratio of qui-square to its degree of freedom $\left(X^{2} / d f\right)$, comparative-of-fit-index (CFI), goodness-of-fit index (GFI), parsimony comparative of-fit index (PCFI), parsimony goodness-of-fit index (PGFI), and root mean square error of approximation (RMSEA). Research practices using these indices state that values for the $X^{2} / d f$ should be less than 3, PCF and PGFI above .60, while values above .95 for the CFI and GFI, and below .06 for the RMSEA represent a good $\mathrm{fit}^{31-34}$.

To study the adequacy of model replication, a multi-group confirmatory factor analysis (MGCFAs) using four steps was conducted with the calibration sample $(n=231)$ and the second sample, as validation sample $(n=222)$, in which we compared four nested models ${ }^{35}$. First, to test configural invariance (i.e., participants from different groups conceptualize the constructs in the same way), we tested the model by constraining the factorial structure to be the same across groups ${ }^{36}$. Second, to test metric invariance (i.e., if different groups respond to the items in the same way), we tested the model by constraining all factor loadings to be the same across groups ${ }^{36}$. Third, to test the scalar invariance (i.e., observed scores are related to the latent scores), we tested the model by constraining the intercepts of items to be the same across groups ${ }^{36}$. Factorial invariance was accepted when the models did not differ significantly $(p>.05)$, according to the qui-square statistic difference ${ }^{22,37}$. However, the qui-square difference statistic is known to reject models even when violations are minor, particularly when the sample size is large ${ }^{38}$. Therefore, we also considered Cheung and Rensvold ${ }^{39}$ suggestion that a difference of CFI of less than or equal to .01 is an indication that the constrained parameters are invariant.

Concurrent validity was analyzed by Pearson's correlation coefficients between the QAD-Fit's and the Doping - related TPB Measures' dimensions ${ }^{20}$, as well as their total score values ${ }^{40}$.

\section{Results}

\section{Preliminary analysis}

The results confirm the univariate normality assumptions, taking into account that absolute values of skewness and kurtosis are below 3 and 7, respectively ${ }^{41}$ (See Table 1). Yet, Mardia's coefficient indicated a lack of multivariate Gaussian distribution $(\text { Coefficient }=63.210)^{42}$. To deal with this, a bootstrapping procedure of Bollen and Stine ${ }^{43}$ was applied to adjust the $p$-value of the chi-square statistic.

Table 1. Factor descriptive statistics for QAD-Fit

\begin{tabular}{lcccccc}
\hline \multicolumn{1}{c}{ Factor } & M & SD & Min & Max & Skewness & Kurtosis \\
\hline Intentions & 2.18 & 1.66 & 1.00 & 7.00 & 1.39 & .76 \\
Attitudes & 2.99 & 1.47 & 1.00 & 7.00 & .67 & -.07 \\
Subjective norms & 1.66 & 1.08 & 1.00 & 6.00 & 1.79 & 2.36 \\
Beliefs & 3.43 & 1.40 & 1.00 & 7.00 & .01 & -.59 \\
Global & 2.57 & 1.15 & 1.00 & 6.75 & .99 & .47 \\
\hline
\end{tabular}

Note. $\mathrm{M}=$ Mean; $\mathrm{SD}=$ Standard Deviation; Min = Minimum; Max $=$ Maximum.

\section{Evaluation of Model Fit}

At first, not all estimated factor loadings exceeded the cut-off point of $.50^{22}$, ranging from .26 to .92 . The goodness-of-fit indices produced for this first-order measurement model indicated poor fit $\left(X^{2}=502.162\right.$, B-S $p<.03 ; X^{2} / d f=3.44$, PCFI $=.81$, PGFI $=.69, \mathrm{CFI}=.94, \mathrm{RMSEA}=.073,90 \% \mathrm{CI}[.066-.081])$ showing that the hypothesized measurement model is inconsistent 
with observed data and it is interpreted as evidence against the adequacy of the model.

Due to the lack of support from CFA performed, post hoc model adjustments were conducted in an effort to develop a better fitting model. The results in the original model (first-order-model) indicated that not all items loaded significantly on its construct. In the interest of scientific parsimony, all scale items that showed unacceptable factor loadings were removed ${ }^{44}$. The number of items eliminated from the model was as small as possible and we tried to leave at least three per factor, in accordance with the recommendation of $\mathrm{O}^{\prime}$ Rourke and Hatcher ${ }^{45}$. Furthermore, the examination of the modification indices (MI) suggested some error correlations that improved the fit of the model. A large error covariance between items 13 and 25 remained present $(\mathrm{MI}=11.560, \mathrm{EPC}=.28)$, suggesting that allowing the two errors to correlate would significantly improve model fit. Examining items 13 ("Selling PES should be punished") and 25 ("Instructors who give PES to their practitioners should be punished"), it was clear that they had a higher degree of overlap. According to Byrne ${ }^{44}$, given the redundancy between both items, we decided to correlate the two errors involved.

The indices of fit indicated a noteworthy improvement of the hypothesized first-order model, as reported in Table 2.

After these procedures, the model adjusted to the data. The results demonstrated an acceptable fit $\left(X^{2}=204.383\right.$, B-S $p<.03 ; X^{2} / d f=2.107, \mathrm{PCFI}=.79, \mathrm{PGFI}=.67, \mathrm{CFI}=.98$, RMSEA $=.049,90 \%$ CI $[.040-.059])$. Composite reliability values ranged from .74 (Beliefs) to .97 (Intentions), indicating that the constructs were internally consistent. Evidence for convergent validity was obtained, since AVE values ranged from .50 (Beliefs) to .87 (Intentions), being greater than the recommended standard of $.50^{24}$.

Furthermore, all constructs were considered to exhibit discriminant validity, because all AVE values exceeded the appropriate square factor correlations. Overall, the measurement model was within the required criteria and showed good psychometric proprieties.

Table 2. QAD-Fit Re-specified first-Order Model-Factor Loading, Z-values, Composite Reliability (CR) and Average Variance Extracted (AVE).

\begin{tabular}{lccccccc}
\hline $\begin{array}{c}\text { QAD-Fit } \\
\text { factors/ } \\
\text { items }\end{array}$ & Loadings & Lower & Upper & $\boldsymbol{p}$ & Z-value & CR & AVE \\
\hline ITENT & & & & & & & \\
Item 20 & .961 & .944 & .974 & .001 & - & & \\
Item 24 & .944 & .926 & .959 & .002 & 45.904 & & \\
Item 18 & .942 & .917 & .959 & .002 & 45.248 & .971 & .871 \\
Item 3 & .879 & .845 & .906 & .002 & 34.054 & & \\
Item 16 & .939 & .920 & .954 & .001 & 44.577 & & \\
\hline ATTITU & & & & & & & \\
Item 30 & .796 & .732 & .853 & .001 & - & & \\
Item 25 & .663 & .596 & .724 & .001 & 13.685 & & \\
Item 32 & .808 & .753 & .854 & .001 & 16.733 & .836 & .507 \\
Item 5 & .652 & .573 & .722 & .001 & 13.513 & & \\
Item 13 & .577 & .499 & .640 & .001 & 11.708 & & \\
\hline
\end{tabular}

(To be continued)
Table 2. QAD-Fit Re-specified first-Order Model-Factor Loading, Z-values, Composite Reliability (CR) and Average Variance Extracted (AVE).

\begin{tabular}{lccccccc}
\hline $\begin{array}{c}\text { QAD-Fit } \\
\text { factors/ } \\
\text { items }\end{array}$ & Loadings & Lower & Upper & $\boldsymbol{p}$ & Z-value & CR & AVE \\
\hline SN & & & & & & & \\
Item 22 & .676 & .587 & .751 & .002 & - & & \\
Item 34 & .821 & .768 & .865 & .002 & 15.628 & .858 & .672 \\
Item 31 & .940 & .876 & .977 & .002 & 16.855 & & \\
\hline BEL & & & & & & & \\
Item 17 & .594 & .530 & .661 & .001 & - & & \\
Item 21 & .713 & .651 & .785 & .001 & 10.678 & .743 & .495 \\
Item 28 & .788 & .711 & .840 & .001 & 11.009 & & \\
\hline
\end{tabular}

Note $:$ ITENT $=$ Intentions; ATTITU $=$ Attitudes; $\mathrm{SN}=$ Subjective norms; BEL $=$ Beliefs.

The data analysis proceeded in an attempt to fit a model with four first-order factors and a second-order-factor. Consequently, we hypothesized that the first order factors are explained by a higher order factor, which in the case of QAD-Fit is a second-order factor designated "behavioral predisposition towards doping". The second-order measured model (Figure 1) showed an overall acceptable fit to the data $\left(X^{2}=208.246\right.$, $\mathrm{B}-\mathrm{S} p<.03 ; X^{2} / d f=2.103, \mathrm{PCFI}=.81, \mathrm{PGFI}=.69, \mathrm{CFI}=.98$, $\mathrm{RMSEA}=.049,90 \%[\mathrm{CI}=.040-.059])$.

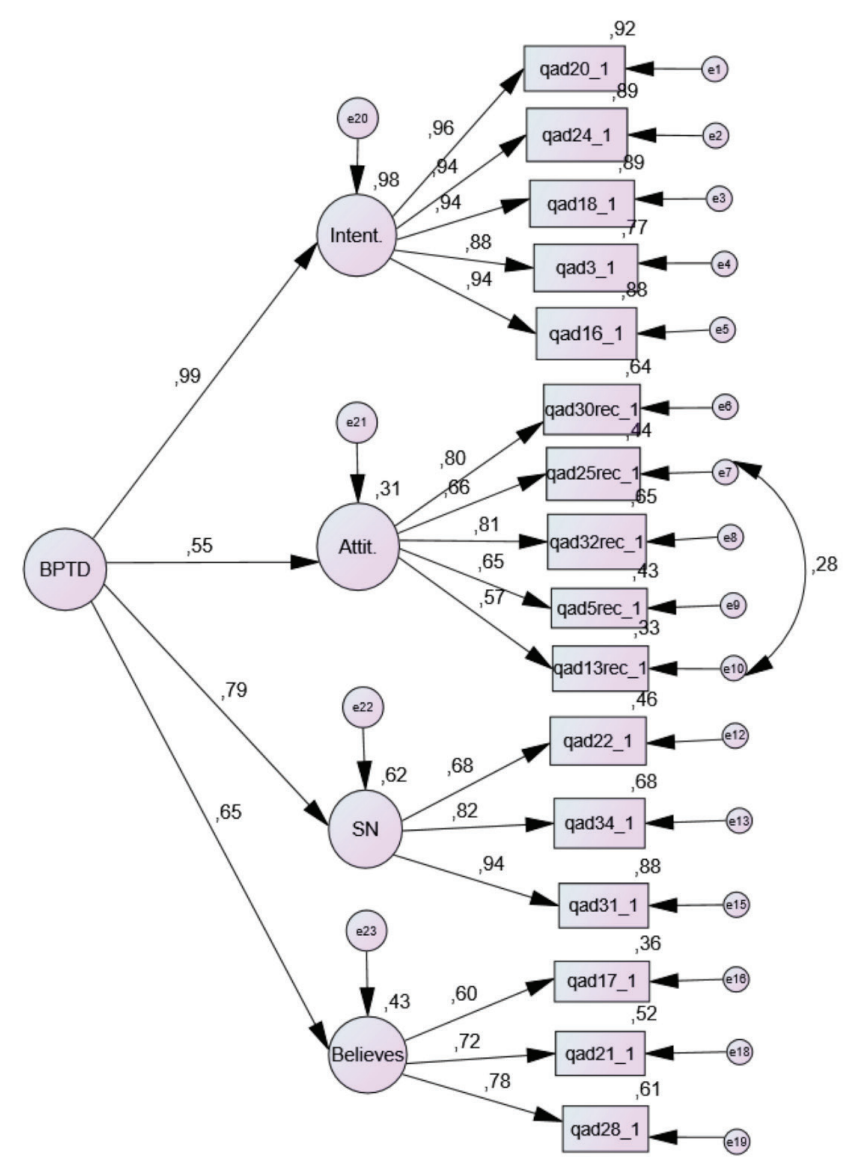

Figure 1. Re-specified second-order model of the QAD-Fit Multidimensional behavioral predisposition towards doping scale. 


\section{Cross-validity}

In order to study the adequacy of model replication, cross-validation procedures were used ${ }^{28}$. More specifically, a cross-validation technique using a multi-group analysis with two equivalent samples in their characteristics ( $n$ calibration sample $=231 ; n$ validation sample $=222$ ) and then a technique of parameter-invariance to verify the equivalence between the two groups ${ }^{26}$. As exposed in Table 3, the fit of the unconstrained model [Model A (full configural invariance): $X^{2}(220)=417.005$ (B-S $p<.03)$; PCFI $=.885$; CFI $=.966$; $\mathrm{RMSEA}=.045]$ was acceptable. The fit of this model provides the baseline value against which all subsequently specified invariance models are compared $^{44}$. The models with constrained factor loadings [Model $\mathrm{B}$ (full metric invariance): $X^{2}(223)=420.658(\mathrm{~B}-\mathrm{S} p<.03$ ); $\mathrm{PCFI}=.897$; CFI $=.966 ; \mathrm{RMSEA}=.044]$, and with constrained intercepts [Model C (full scalar invariance): $X^{2}(239)=444.369$ $(\mathrm{B}-\mathrm{S} p<.03)$; PCFI $=.960$; $\mathrm{CFI}=.964$; RMSEA $=.044]$, showed a satisfactory fit. The $X^{2}$ statistic showed no significant differences between Model A and Model B $\left[X^{2} \operatorname{dif}(3)=3.653\right.$; $p=.301]$ and also no significant differences between Model A and Model C $\left[X^{2} \operatorname{dif}(19)=27.364 ; p=.096\right]$. There were no differences in the CFI values for all model comparisons. Thus, the results demonstrated the model's invariance in both samples, indicating that the factorial structure of the scale was stable in the two independent samples ${ }^{39}$.

Table 3. Results of the Multi-Group Analysis across the Unconstrained Model and the Constrained Models of the QAD-Fit (Calibration sample: $\mathrm{n}=231$; Validation sample: $\mathrm{n}=222$ )

\begin{tabular}{|c|c|c|c|c|c|c|c|c|}
\hline Multi-Group models & $X^{2}$ & $d f$ & $\Delta X^{2}$ & $\Delta d f$ & B-S $p$ & CFI & PCFI & RMSEA \\
\hline Model A & 417.005 & 220 & - & - & - & .966 & .885 & .045 \\
\hline Model B & 420.658 & 223 & $3.653 *$ & 3 & $<.03$ & .966 & .897 & .044 \\
\hline Model C & 444.369 & 239 & $27.363 *$ & 19 & $<.03$ & .964 & .960 & .044 \\
\hline
\end{tabular}

Note. $X^{2}=$ chi-square; $d f=$ degrees of freedom; $\Delta X^{2}=$ chi-square difference; $\Delta d f=$ degrees of freedom difference; B-S $p=$ Bolen-Stine $p$-value; $\mathrm{CFI}=$ comparative fit index; PCFI = parsimony comparative fit index; GFI = goodness of fit index; PGFI = parsimony goodness of fit index; RMSEA $=$ root mean square error of approximation.

$* p$-value $>.05$.

\section{Concurrent validity}

Assessing concurrent validity involves comparing a new test with an existing test (of the same nature) to verify if they produce similar results. If both tests produce similar results, then the new test is said to have concurrent validity. In this case, we used the Portuguese version of the Doping-related TPB Measures ${ }^{20}$ to compare with the "Questionnaire of Attitudes towards Doping in Fitness" (QAD-Fit).

In accordance with the previously mentioned, the Doping-related TPB Measure ${ }^{20}$ was translated, adapted and validated in Portuguese for concurrent validity purposes.

Once approval was obtained from the original author, the translation of the Doping-related TPB Measure ${ }^{20}$ was performed, according to Beaton, Bombardier, Guillemin, Ferraz, Bosi ${ }^{21}$ guidelines.

The procedures adopted were similar to those used in QAD-Fit (participants, data collection and data analysis).

The results obtained for the CFA of the Portuguese version of the Doping-related TPB Measures, indicated that not all items loaded significantly on its construct, according to the original model $(4 \text { factors })^{20}$. Due to the lack of support from CFA performed, post hoc model adjustments were conducted in an effort to develop a better fitting model. After these procedures, we obtained a first-order model with only three factors (attitudes, subjective norms and behavior intentions) and 11 items, adjusted to the data (Table 4). The factor perceived behavior control was removed from the analysis considering that the items don't meet AFC criteria. Lucidi, Zelli, Mallia, Grano, Russo, Violani ${ }^{20}$, in their validation of the scale, founded also poor but satisfactory indicators of reliability for this factor.

Our results demonstrated an acceptable fit $\left(X^{2}=110.697\right.$; $p=.000 ; X^{2} / d f=2.77 ; \mathrm{PCFI}=.72 ; \mathrm{PGFI}=.58 ; \mathrm{CFI}=.99$; RMSEA $=.06,90 \%$ CI [.049 - .077]). Composite reliability values ranged from .80 (Subjective Norms) to .96 (Intentions), indicating that the constructs were internally consistent. Evidence for convergent validity was obtained, since AVE values ranged from .66 (Subjective Norms) to .90 (Intentions), being greater than the recommended standard of $.50^{24}$.

Furthermore, all constructs were considered to exhibit discriminant validity, because all AVE values exceeded the appropriate square factor correlations. Overall, the measurement model was within the required criteria and showed good psychometric properties.

The data analysis proceeded in an attempt to fit a second-order-factor model. The second-order measured model showed, as expected, an overall acceptable fit to the data $\left(X^{2}=110.697 ; p=.000 ; X^{2} / d f=2.77 ; \mathrm{PCFI}=.72 ; \mathrm{PGFI}=.58\right.$; CFI $=.99 ;$ RMSEA $=.06,90 \%$ CI $[.049-.077])$.

In order to study the adequacy of model replication, cross-validation procedures were used ${ }^{28}$, using a multi-group analysis with two equivalent samples in their characteristics $(n$ calibration sample $=231 ; n$ validation sample $=222)$ and then a technique of parameter-invariance to verify the equivalence between the two group ${ }^{26}$. The fit of the unconstrained model [Model A: $X^{2}(80)=168.525 ; \mathrm{PCFI}=.716 ; \mathrm{PGFI}=.570 ; \mathrm{CFI}=.984$; $\mathrm{GFI}=.940 ; \mathrm{RMSEA}=.050]$ was acceptable. The fit of this model provides the baseline value against which all subsequently specified 
invariance models are compared ${ }^{44}$. The models with constrained factor loadings [Model B $\left(: X^{2}(88)=174.468\right.$; PCFI $=.788$; $\mathrm{PGFI}=.625 ; \mathrm{CFI}=.984 ; \mathrm{GFI}=.938 ; \mathrm{RMSEA}=.047]$, and with constrained variances/covariances [Model C: $X^{2}(91)=178.016$; $\mathrm{PCFI}=.814 ; \mathrm{PGFI}=.646 ; \mathrm{CFI}=.984 ; \mathrm{GFI}=.937 ; \mathrm{RMSEA}=.046]$, showed a satisfactory fit. The $X^{2}$ statistic showed no significant differences between Model A and Model B [ $X^{2} \operatorname{dif}(8)=5.943$; $p=.654]$ and also no significant differences between Model A and Model C $\left[X^{2} \operatorname{dif}(11)=9.491 ; p=.577\right]$. There were no differences in the CFI values for all model comparisons. Thus, the results demonstrated the model's invariance in both samples, indicating that the factorial structure of the scale was stable in the two independent samples.

Table 4. Portuguese version of DRTPBM Re-specified first Order Model-Factor Loading, Z-values, Composite Reliability (CR) and Average Variance Extracted (AVE).

\begin{tabular}{lcccc}
\hline $\begin{array}{c}\text { DRTPBM } \\
\text { factors/items }\end{array}$ & Loadings & Z-value & CR & AVE \\
\hline BITENT & .870 & 23.434 & & \\
Item 1 & .999 & 30.029 & .963 & .898 \\
Item 2 & .969 & 28.277 & & \\
Item 3 & & & & \\
\hline ATTITU & .731 & 17.877 & & \\
Item 1 & .806 & 20.587 & & \\
Item 2 & .902 & 24.612 & .943 & .734 \\
Item 3 & .960 & 27.496 & & \\
Item 4 & .873 & 23.315 & & \\
Item 5 & 851 & 22.350 & & \\
Item 6 & & & & \\
\hline SN & .846 & 19.054 & .795 & .660 \\
Item 1 & .777 & 17.325 & .795 \\
Item 2 &
\end{tabular}

Note: BITENT = Behavior Intentions; ATTITU = Attitudes; $\mathrm{SN}=$ Subjective norms.

By studying the concurrent validity based on the interrelations between the scores of the two questionnaires, we obtained the results presented in Table 5, related to the correlations between QAD-Fit and the Portuguese version of the Doping-related TPB Measures. Results reveal that the two scales were positively correlated. The attitudes towards doping scores were also positively related to behavioral intentions, attitudes, and subjective norms and total Portuguese version of the Doping related TPB Measures scores.

Table 5. Correlation Matrix between QAD-Fit and Portuguese version of DRTPBM.

\begin{tabular}{cccccc}
\hline \multirow{2}{*}{ Scales } & QAD- & QAD- & QAD- & QAD- & QAD- \\
& Fit- A & Fit-SN & Fit-I & Fit- B & Fit- TS \\
\hline DRTPBM- A & $.535^{* *}$ & $.499^{* *}$ & $.657^{* *}$ & $.535^{* *}$ & $.659^{* *}$ \\
DRTPBM- SN & $.536^{* *}$ & $.471^{* *}$ & $.615^{* *}$ & $.510^{* *}$ & $.618^{* *}$ \\
DRTPBM- BI & $.463 * *$ & $.573 * *$ & $.666^{* *}$ & $.502^{* *}$ & $.668^{* *}$ \\
DRTPBM- TS & $.570^{* *}$ & $.576^{* *}$ & $.724 * *$ & $.577 * *$ & $.727 * *$ \\
\hline
\end{tabular}

Note: QAD-Fit- A = Attitudes; QAD-Fit-SN = Subjective Norms; QAD-Fit-I = Intentions; QAD-Fit- B = Beliefs; QAD-Fit- TS = Total score; DRTPBM- A = Attitudes; DRTPBM- SN = Subjective Norms; DRTPBM- BI = Behavior Intentions; DRTPBM- TS = Total score ** Bolen-Stine $p<.01$.

\section{Discussion}

The purpose of this study was to test the factorial validity of the "Questionnaire of Attitudes towards Doping in Fitness" (QAD-Fit), originally developed by Serpa, Leitão, Marcolino, Faria, Ramadas, Reis ${ }^{16}$, in a Portuguese gym/fitness practitioner's population.

The confirmatory factorial analysis performed on QAD-Fit with a sample of $453 \mathrm{gym} /$ fitness practitioners confirmed the factorial structure (four-factor) similar to the original version ${ }^{16}$. However, some items revealed unacceptable factor loadings on their different constructs and were eliminated. The differences between the two forms are minimal and shorten the questionnaire. In this way, the scale modifications resulted in a shortened questionnaire containing 16 items, representing the original four factors ${ }^{16}$. A short questionnaire is preferable in terms of gym/fitness settings, considering the practical conditions of application.

The factor analysis using the re-specified model showed an acceptable fit of the data and confirmed the four first-order constructs, as well as a second-order construct. The model showed composite reliability, convergent and discriminant validity.

Furthermore, the model invariance in the two independent samples was supported, indicating the comparisons are valid and differences/similarities between groups can be meaningfully interpreted $^{36}$ (cross-validity). According to Mâroco ${ }^{37}$, this is a pivotal step when evaluating the psychometric properties of a scale, and this procedure has been reported when validating scales in recent studies conducted in the sports scenario (e.g. Correia, Rosado and Serpa ${ }^{46}$; Martins, Rosado, Ferreira and Biscaia ${ }^{47}$ ). Therefore, the use of model invariance in the two independent samples on the present study could be considered strong and an important finding to highlight about the QAD-Fit, representing a contribution to the measure of the attitudes towards PES consumption in this specific population (gym users), since the study by Serpa, Leitão, Marcolino, Faria, Ramadas, Reis ${ }^{16}$ did not consider this validation procedure.

QAD-Fit's concurrent validity has been ascertained with the Portuguese version of DRTPBM and, as expected, scores showed appropriate concurrent validity with measures of attitudes, subjective norms and behavioral intentions ${ }^{20}$, providing additional support for its construct validity.

All dimensions of the QAD-Fit showed a statistically significant relationship with the second-order construct (behavioral predisposition towards doping), with the strongest predictor being Intentions. This factor concerns reasons leading to take or not take PES, followed by subjective norms, that is, the subject's perception of what significant people (instructors, colleagues, relatives) think about the consumption of PES and in third place comes beliefs, which relates to the subject's views regarding the effect of PES in order to achieve goals and to improve the performance and physical appearance, and the last factor is attitudes towards PES consumption, that is, the evaluative component of such behavior by the subject, reinforcing the idea that the understanding of attitudes towards doping will possibly be one of the first steps to consider in the study of the associated psychological factors ${ }^{17}$. The study and measures 
of attitudes through QAD-Fit use, complemented with other tools (e.g., interviews ${ }^{48}$, Implicit Association Test (IAT) ${ }^{49}$ or biochemical tests ${ }^{4,50}$ could contribute to effective and ecologically valid intervention strategies for gym/fitness practitioners, towards doping prevention.

\section{Limitations}

Finally, although results provide support to QAD-Fit psychometric characteristics, there are limitations that need to be acknowledged. First, further replications with the resulting model must be done in the future and with other populations, since post hoc procedures were used, which refined the measurement instrument (though this approach does not compromise the integrity of the prior model ${ }^{51}$ ). Second, this study is a cross-sectional survey, and, as such, its findings do not inform about the concretization of the behavior of doping consumption in those who showed positive attitudes to doping. Future research will benefit from longitudinal designs for attaining predictive validity of the QAD-Fit version and mixed-method approaches might be particularly conducive to the study of a set of circumstances and contradictions which could possibly characterize one's experience with PES use in the context of gym/fitness settings?

\section{Conclusions}

The findings of this present research revealed that QAD-Fit is a psychometrically valid and reliable instrument for researchers, fitness center instructors, physicians and psychologists, who want to assess attitudes towards doping consumption in gym/fitness settings, thus filling the identified gap in this area of knowledge ${ }^{4}$. At the same time, this scale could be considered a possible solid measurement tool for further studies on the doping attitude, which could allow direct comparisons and meta-analyses of independent studies, thus serving the scientific community involving doping research.

\section{References}

1. The European Health \& Fitness Association. Final report section 3 - definitions and background. Bruxelles; 2012. Available from: http://www.fitness.be/src/Frontend/Files/.../Final_Report_280212. pdf [Accessed 14th June 2018].

2. Tavares AS, Serpa S, Horta L, Rosado A. Psychosocial factors and performance enhancing substances in gym users: A systematic review. Rev Psicol del Deport/J Sport Psychol. 2019;28(1): in press.

3. Ntoumanis N, Ng J, Barkoukis V, Backhouse S. Personal and Psychosocial Predictors of Doping Use in Physical Activity Settings: A Meta-Analysis. Sport Med. 2014 Nov;44(11):1603.

4. Morente-Sánchez J, Femia-Marzo P, Zabala M. Cross-cultural adaptation and validation of the Spanish version of the $\mathrm{P}$ performance enhancement attitude scale ( Petróczi, 2002 ). J Sport Sci Med. 2014;13(February):430-8.
5. Soltanabadi S, Tojari F, Manouchehri J, Sciences S, Branch CT. Validity and reliability of measurement instruments of doping attitudes and doping behavior in Iranian. Indian J Fundam Appl Life Sci. 2014;4(S4):280-6.

6. Petróczi A, Backhouse SH, Barkoukis V, Brand R, Elbe A-M, Lazuras L, et al. A call for policy guidance on psychometric testing in doping control in sport. Int J Drug Policy. 2015;26(11):1130-9. doi: 10.1016/j.drugpo.2015.04.022.

7. Barkoukis V, Lazuras L, Tsorbatzoudis H. The psychology of doping in sport. New York: Routledge, 2016. 248 p.

8. Kavussanu M, Ring C. Moral identity predicts doping likelihood via moral disengagement and anticipated guilt. J Sport Exerc Psychol. 2017;39(4):293-301. doi: 10.1123/jsep.2016-0333.

9. Chan DKC, Hardcastle S, Dimmock JA, Lentillon-Kaestner V, Donovan RJ, Burgin M, et al. Modal salient belief and social cognitive variables of anti-doping behaviors in sport: Examining an extended model of the theory of planned behavior. Psychol Sport Exerc. 2015;16(P2):164-74. doi: 10.1016/j.psychsport.2014.03.002

10. Armitage CJ, Conner M. Social cognition models and health behaviour: A structured review. Psychol Health. 2000;15(2):173-89. doi: 10.1080/08870440008400299.

11. Armitage CJ, Conner M. Efficacy of the Theory of Planned Behaviour: A meta-analytic review. Br J Soc Psychol. 2001;40:471-99.

12. Ajzen I. The Theory of Planned Behavior. Organ Behav Hum Decis Process. 1991;50:179-211.

13. Kirby K, Guerin S, Moran A, Matthews J. Doping in elite sport. In: Barkoukis, Vassilis; Lazuras LTH, editor. The Psychology of Doping in Sport. London and New York: Routledge; 2016. p. 3-17.

14. Hauw D, Roten FC Von, Mohamed S, Philippe RA. Psychometric properties of the French-language version of the Performance Enhancement Attitude Scale ( PEAS ). Rev Eur Psychol Appl. 2016;66(1):15-21. doi: 10.1016/j.erap.2015.09.003.

15. Petróczi A, Aidman E. Measuring explicit attitude toward doping : Review of the psychometric properties of the Performance Enhancement Attitude Scale. Psychol Sport Exerc. 2009;10(3):3906. doi:10.1016/j.psychsport.2008.11.001.

16. Serpa S, Leitão J, Marcolino P, Faria N, Ramadas S, Reis C. Psychological aspects of doping in sports: development of the "Questionnaire of attitudes towards doping." In: A. Papaioannou MG\& YH, editor. 10th World Congress of Sport Psychology, Skiathos, Greece, June/July 2001. University of Thessaly \& Hellenic Society of Sport Psychology; 2001.

17. Serpa S, Faria N, Marcolino P, Reis C, Ramadas S. Dopagem e psicologia. Lisboa: Centro de Estudos e Formação Desportiva, 2003.

18. Opdenacker J. Attitudes towards doping and motivation to practice sports in 14 to 18 year old athletes. Leuven.Thesis [Master in Sport and Exercise Psychology.] -Katholieke Universiteit; 2004.

19. Soper, D. S. A-priori sample size calculator for structural equation models [Software]. Available from: https://www.danielsoper.com/ statcalc/calculator.aspx?id=89 [Accessed 18th June 2017].

20. Lucidi F, Zelli A, Mallia L, Grano C, Russo PM, Violani C. The social-cognitive mechanisms regulating adolescents' use of doping substances. J Sports Sci. 2008;26(5):447-56. doi: 10.1080/02640410701579370.

21. Beaton DE, Bombardier C, Guillemin F, Ferraz, Bosi M. Guidelines for the process of cross-cultural adaptation of self report measures. Spine. 2000; 25(24):3186-3191. 
22. Loehlin JC. Latent variable models: An Introduction to factor, path, and structural equation analysis. Mahwah: Lawrence Erlbaum Associates. 2003.

23. West SG, Finch JF, Curran PJ. Structural equation models with nonnormal variables: Problems and remedies. In: Hoyle RH, editor. Structural equation modeling: Concepts, issues, and applications. Thousand Oaks, CA, US: Sage Publications, Inc., 1995. p. 56-75.

24. Fornell C, Larcker D. Evaluating structural equation models with unobservable variables and measurement error. J Marketing Res. 1981; 18(3): 39-50.

25. Hair J, Anderson R, Tatham R, Black W. Multivariate data analysis. Upper Saddle River: Prentice Hall, 2009.

26. Brown T. Confirmatory factor analysis for applied research. New York: The Guildford Press, 2006. 475 p.

27. Davey A, Savla J. Statistical power analysis with missing data: A structural equation modeling approach. New York: Taylor and Francis Group, 2010. 369 p.

28. Schumacker RE, Lomax RG. A beginner's guide to structural equation modeling. 2nd ed. Mahwah: Psychology Press, 2004.

29. Hu LT, Bentler PM. Cutoff criteria for fit indexes in covariance structure analysis: Conventional criteria versus new alternatives. Struct Equ Model. 1999;6(1):1-55.

30. Marsh HW. Application of confirmatory factor analysis and structural equation modeling in sport and exercise psychology. In: Tenenbaum G, Eklund RC, editors. Handbook of sport psychology. New York: Wiley, 2007. p. 774-798.

31. Arbuckle JL. Amos 18 reference guide (version 18). Amos 18 User's Guide. Chicago, IL: Statistical Package for the Social Science, 2009. $635 \mathrm{p}$.

32. Bentler PM, Bonett DG. Significance tests and goodness of fit in the analysis of covariance structures. Psychol Bull. 1980;88(3):588-606.

33. Blunch NJ. Introduction to structural equation modelling using SPSS and AMOS. London, England: SAGE, 2008.

34. Kline RB. Principles and practice of structural equation modeling. New York: Guilford, 1998

35. Vandenberg RJ, Lance CE. A review and synthesis of the measurement invariance literature: Suggestions, practices, and recommendations for organizational research. Organ Res Methods. 2000;3(1):4-70.

36. Milfont TL, Fischer R. Testing measurement invariance across groups: Applications in cross- cultural research. Int J Psychol Res. 2010;3(1):111-21.

37. Marôco J. [Análise de equações estruturais: Fundamentos teóricos, software e aplicações]. 2nd ed. Pêro Pinheiro, Portugal: Report Number; 2014. 389 p. Portuguese.

38. Chen FF. Sensitivity of goodness of fit indexes to lack of measurement invariance. Struct Equ Model. 2007;14(3):464-504.

39. Cheung G, Rensvold R.Evaluating goodness-of-fit indexes for testing measurement invariance. Struct Equ Modeling: A Multidisciplinary Journal. 2002;9(2):233-255.

40. Campbell D, Fiske D. Convergent and discriminant validation by the multitrait-multimethod matrix. Psychol Bull. 1959;56(2):81-105.

41. Kline RB. Beyond significance testing: Reforming data analysis methods in behavioral research. Washington: American Psychological Association, 2004. 325 p.
42. Bentler PM, Wu EJC. EQS/windows user's guide. Los Angeles: BMDP Statistical Software, 1993. 180 p.

43. Bollen KA, Stine RA. Bootstrapping goodness-of-fit measures in structural equation models. In: Bollen, Long J, editors. Testing structural equation models. Newbury Park: SAGE Focus Edition, 1993. p. 111-135.

44. Byrne BM. Structural equation modeling with Amos: Basic concepts, applications, and programming. New York: Taylor and Francis Group, 2010. 2009 p. doi: 10.4324/9781410600219.

45. O’Rourke N, Ph.D., R.Psych., Hatcher L. A step-by-step approach to using sas ${ }^{\circledR}$ for factor analysis and structural equation modeling. 2nd Ed. North Carolina: SAS Institute Inc., Cary, 2013. 444 p. doi: 10.1111/insr.12111_2.

46. Correia M, Rosado A, Serpa S. Fear of failure in sport : A Portuguese cross-cultural adaptation. Motriz: J. Phys. Ed. 2016;22(4):376-382. doi: 10.1590/S1980-6574201600040024.

47. Martins P, Rosado A, Ferreira V, Biscaia R. Examining the validity of the Athlete Engagement Questionnaire (AEQ) in a Portuguese sport setting. Motriz: J. Phys. Ed. 2014;20(1):1-7. doi:10.1590/ S1980-65742014000100001.

48. Lentillon-kaestner V, Hagger MS, Hardcastle S. Health and doping in elite-level cycling. Scand J Med Sci Sports. 2012;22(5):596-606. doi: 10.1111/j.1600-0838.2010.01281.x.

49. Brand R, Wolff W, Thieme D. Using response-time latencies to measure athletes ' doping attitudes : the brief implicit attitude test identifies substance abuse in bodybuilders. Subst Abus Treat Prev Policy. 2014;9(36):1-10.

50. Morente-Sánchez J, Zabala M. Doping in sport: A review of elite athletes attitudes, beliefs, and knowledge. Sport Med. 2013;43(6):395411. doi: 10.1007/s40279-013-0037-x.

51. Hofmann R. Establishing factor validity using variable reduction in confirmatory factor analysis. Educ Psychol Meas. 1995;55:572-582.

\section{Corresponding author}

Ana Sofia Tavares

Institution: H\&TRC- Health \& Technology Research Center, ESTeSL- Escola Superior de Tecnologia da Saúde de Lisboa, Instituto Politécnico de Lisboa.

Av. D. João II, Lote 4.69.01 | 1990-096 Lisboa, Portugal

Email: ana.tavares@estesl.ipl.pt

Manuscript received on November 20, 2018

Manuscript accepted on March 10, 2019

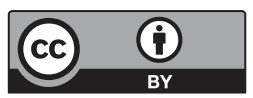

Motriz. The Journal of Physical Education. UNESP. Rio Claro, SP, Brazil - eISSN: 1980-6574 - under a license Creative Commons - Version 4.0 


\section{Appendix}

\section{QAD-Fit}

3. Tomaria substâncias que melhoram o desempenho para conseguir concretizar os meus objetivos de prática da atividade física.

5. Quando o praticante se classifique em competições devido à ingestão de substâncias que melhoram o desempenho, deveria ser desclassificado.

13. Deveria ser punida a venda de substâncias que melhoram o desempenho.

16. Para obter a aparência física que desejo, eu tomaria substâncias que melhoram o desempenho.

17. As substâncias que melhoram o desempenho ajudam a melhorar as capacidades físicas.

18. Para aumentar as minhas capacidades físicas, eu tomaria substâncias que melhoram o desempenho.

20. Para ter um físico mais perfeito, eu tomaria substâncias que melhoram o desempenho.

21. O consumo de substâncias que melhoram o desempenho, ajuda a desenvolver a autoconfiança.

22. Eu tomaria substâncias que melhoram o desempenho, se a maioria das pessoas que conheço aprovassem.

24. Para conseguir atingir um objetivo que desejo muito, eu tomaria substâncias que melhoram o desempenho.

25. Os instrutores que dão substâncias que melhoram o desempenho aos seus praticantes deveriam ser punidos.

28. O consumo substâncias que melhoram o desempenho ajuda o bem-estar dos praticantes.

30. O consumo substâncias que melhoram o desempenho é uma forma de batota.

31. Para ser admirado (a) fisicamente, eu tomaria substâncias que melhoram o desempenho.

32. Um praticante deve atingir os seus objetivos por si próprio e não com a ajuda de substâncias que melhoram o desempenho.

34. Para agradar fisicamente aos outros, eu tomaria substâncias que melhoram o desempenho.

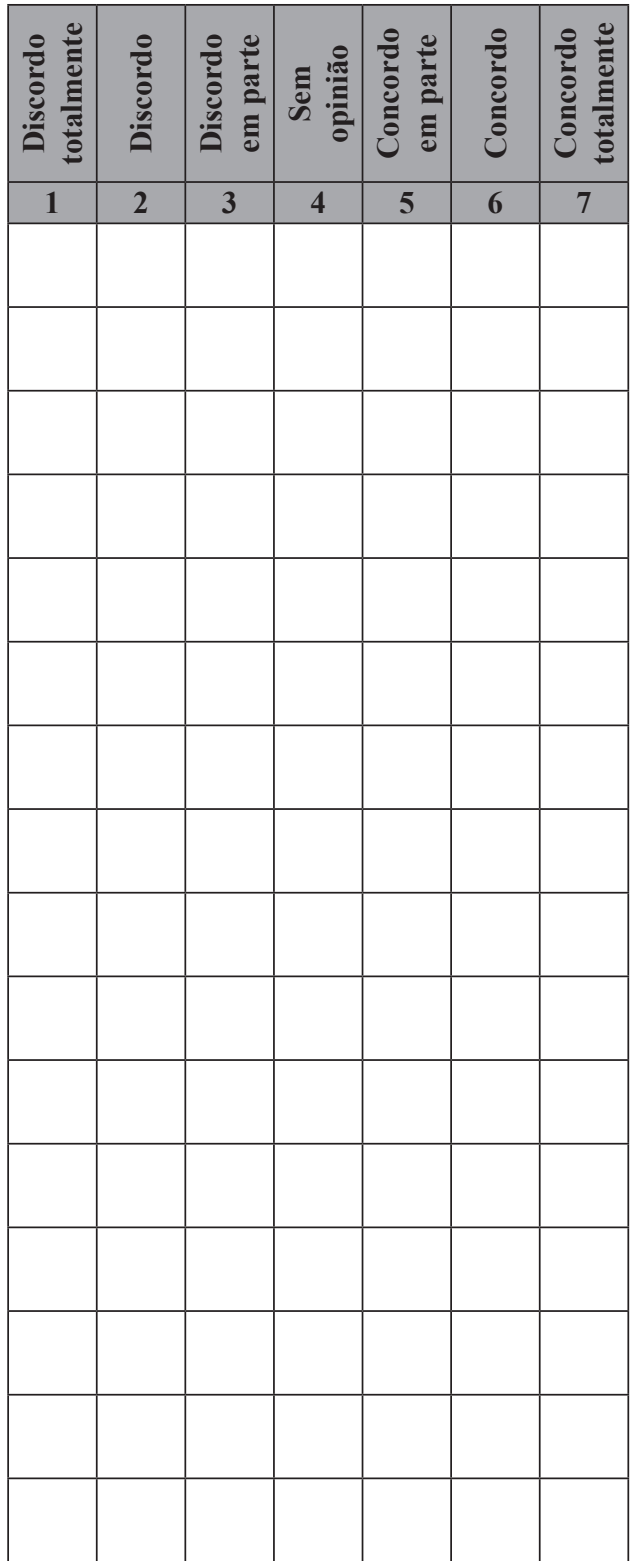

